\title{
REZENSIONEN
}

\section{Herzog und Köbler: zwei Bundespräsidenten in Nahaufnahme}

Herzog, Roman: Jahre der Politik. Die Erinnerungen, Siedler Verlag, München 2007, 416 Seiten, € 22,95.

Langguth, Gerd: Horst Köhler. Biografie, dtv, München 2007, 413 Seiten, € 15,-.

Roman Herzog - Horst Köhler: Der eine war der siebte, der andere ist der neunte Bundespräsident der Bundesrepublik Deutschland. Der eine hatte als CDU-Politiker, Wissenschaftler und Jurist Karriere gemacht, es gar bis zum Präsidenten des Bundesverfassungsgerichts gebracht, ehe er 1994 das protokollarisch höchste Amt im Staate übernahm. Vom anderen hatten die wenigsten gehört, als ihn CDU/CSU und FDP 2004 als Kandidaten für das Amt des Bundespräsidenten aus dem Hut zauberten. Eingeweihten war Köhler zwar als Fachmann für Währungsfragen und Finanzpolitik bekannt, doch öffentlich hatte er sich bis dahin nicht profilieren können (und wohl auch nicht profilieren wollen). So unterschiedlich wie die Lebenswege von Herzog und Köhler sind die hier zu besprechenden Bücher. Gerd Langguth hat eine - tatsächlich ist es die erste - Biografie über Horst Köhler vorgelegt, und Roman Herzog hat „Erinnerungen“ über seine Jahre in der Politik verfasst.

Gerd Langguth, Professor für Politikwissenschaft an der Universität Bonn, ist ein erfahrener Biograf. Er schreibt flüssig, weiß, Geschichten zu erzählen, kann recherchieren und durch Interviews mit Zeitzeugen bisweilen Neues herausfinden oder nur gerüchteweise Bekanntes durch Fakten substanziieren. All dies gelang ihm in seinem Buch über Angela Mer$k e l^{1}$, gelingt ihm mit der Biografie über Horst Köhler jedoch nur stellenweise. Dabei folgt seine Studie den ungeschriebenen Regeln politischer Biografien. Herkunft, familiärer Hintergrund und beruflicher sowie politischer Aufstieg werden in chronologischer Ordnung beschrieben und zeitgeschichtlich unterfüttert. Allein die Einleitung, das Kapitel über die Ehefrau des Bundespräsidenten, Eva Köhler, sowie die abschließenden Thesen folgen nicht dieser Darstellungsweise. Anschaulich schildert Langguth die Herkunft Köhlers, der als siebtes von acht Kindern 1943 zur Welt kam. Man erfährt einiges über Kindheit und frühen Werdegang wie zum Beispiel, dass die Eltern Bauern in Bessarabien waren und 1940 nach Polen übersiedelten, dass die Familie 1944 nach Sachsen und 1953 ins Schwabenland floh, wo sie schließlich 1957 in Ludwigsburg ihre endgültige Heimat fand, dass Köhler in der Schule „wohl nur im Sport wirklich gut" war (S. 52), ein „fleißiger Studiosus “ wurde (S. 60 ff.), 1965 in die Studentenverbindung „Normannia“ eintrat (S. 64), seinen Vater früh verlor (S. 61) und seine Frau zwischen 1972 und 1990 Mitglied der SPD war (S. 69). Auch die beruflichen Stationen werden ausführlich beschrieben, wobei besonders die Analyse hervorsticht, wie Angela Merkel und Guido Westerwelle Köhler zum Präsidentschaftskandidaten kürten (S. $201 \mathrm{ff}$.).

1 Gerd Langguth, Angela Merkel. Aufstieg zur Macht, 2. Auflage, München 2007.

Zeitschrift für Parlamentsfragen (ZParl), Heft 1/2008, S. 169 - 190 
Langguth scheint Köhler als Politiker und Verwaltungsfachmann nicht besonders zu schätzen, auch wenn er dessen Leistungen als Finanz- und Währungsexperte durchaus anerkennt. Doch als Bundespräsident ist Köhler - so lässt sich Langguths Urteil vereinfachend zusammenfassen - eine Fehlbesetzung. Er sei ein Mann „ohne politische Eigenschaften“ (S. 323) mit einer „obrigkeitlich-exekutiven“ Erfahrungswelt (S. 325), darüber hinaus ein „unsicherer Mann" (S. 332), der zu Zornausbrüchen neige und über keine über das Ökonomische hinausreichende politische Vision verfüge. Er besitze gar nur „mangelnd[e] Sprachkenntnisse" (S. 327), was überrascht angesichts der Funktionen, die Köhler sowohl in London bei der Europäischen Bank für Wiederaufbau und Entwicklung als auch in Washington beim Internationalen Währungsfonds innehatte. Köhlers Aufstieg ist nach Langguth vor allem Resultat seines ,legendären Fleiß[es] und seiner rastlosen Hingabe für die ihm übertragenen Aufgaben" (S. 326).

All dies ist ohne Zweifel gut präsentiert und interessant zu lesen. Doch Langguths Untersuchung weist zwei Mängel auf. Zum einen gewinnen die Beschreibungen selten an Tiefe. Beispielsweise bleibt Köhlers Verhältnis zu seiner Familie im Grunde unklar. So wird der Tod des Vaters eher protokolliert als in seiner Bedeutung für den Sohn erschlossen. Immer wieder berichtet Langguth auch über Köhlers Ungeduld und dessen Neigung zum Jähzorn (S. 148, S. 172, S. 175), doch bleibt dies zumeist nur schwach belegt. Selten ist der Biograph in der Lage, in den Medien Berichtetes mit eigenen Quellen zu bestätigen oder zu korrigieren. Das kann auch nicht anders sein, da Langguth „kein[en] oder kaum Zugang zu Archivmaterial“ (S. 349) hatte und auch Horst Köhler zu keinem Gespräch bereitstand. Ein solches Quellendefizit muss Folgen haben, die besonders zum Tragen kommen, wenn Langguth die Präsidentschaft Köhlers beschreibt. Hier kommt die Darstellung nie über das ohnehin Bekannte hinaus.

Zum anderen ist zu fragen, welchem Zweck ein Buch über einen Bundespräsidenten dienen soll, der bei Erscheinen gerade einmal wenig mehr als die Hälfte der ersten Amtszeit hinter sich hat. Die Biographie kann daher nichts aussagen über Köhlers Vorschlag, den Bundespräsidenten direkt vom Volk wählen zu lassen, über seine Entscheidung, das Gnadengesuch von Christian Klar abzulehnen, oder über die Kritik an zu hohen Managergehältern, um nur wenige Interventionen Köhlers aus dem Jahre 2007 anzuführen. Man kann sich mithin des Eindrucks nicht erwehren, dass die Veröffentlichung weniger dazu dienen sollte, die Person Horst Köhler zu erklären, die Wirkung des neunten Bundespräsidenten auf die politische Entwicklung Deutschlands zu erschließen oder Zeitgeschichte zu vermitteln. Vielmehr liegt das größte und keineswegs gering zu schätzende Verdienst Langguths darin, die erste Biographie über Horst Köhler vorgelegt zu haben. Darin liegt zugleich deren Beschränkung.

Von ganz anderer Art sind die Hypotheken, die Roman Herzogs „Erinnerungen“ belasten. Herzog wollte nie Memoiren schreiben, denn von „Lebenserinnerungen, die sich teils wie Familiengeschichten und teils wie Bildungsromane lesen", hält der Autor nicht viel (S. 9). Außerdem hätten ihn seine Ämter ,in den interessantesten Fragen zur Vertraulichkeit" verpflichtet (S. 9). Herzog hält sich durchweg an seine selbst gesetzten Vorgaben, was ihm hoch anzurechnen ist, aber die Frage aufwirft, wozu Erinnerungen eines öffentlichen Amtsträgers über seine Jahre in der Politik dienen können, wenn sie weder persönlich sein noch einen Blick erlauben sollen hinter die Kulissen der Politik.

Man liest die „Erinnerungen“ aus demselben Grund wie Langguths Biographie: weil man etwas über Bundespräsidenten erfahren möchte. Die Zeit, die Herzog im Schloss Belle- 
vue amtierte, bildet denn auch das Herzstück der „Erinnerungen“. Darüber hinaus beschreibt er kurz seinen familiären Hintergrund sowie den Beginn seiner wissenschaftlichen Karriere. Etwas ausführlicher geht Herzog auf seine Jahre als Bevollmächtigter des Landes Rheinland-Pfalz beim Bund, als Kultus- und Innenminister in Baden-Württemberg und als Richter beim Bundesverfassungsgericht ein, allerdings ohne Blicke hinter die Kulissen zuzulassen (abgesehen von kleinen Spitzen, die Herzog gelegentlich gegen Johannes Rau richtet, S. 86 f., S. 154).

Auch sonst bleibt Herzog den selbst gesetzten Vorgaben treu. Dabei weist seine Darstellung einige schwer erklärbare Lücken auf. So hätte man schon gern gewusst, was er über seinen ehemaligen Lehrer Theodor Maunz denkt, einen der „furchtbaren Juristen“ des Dritten Reiches, der, immerhin Ko-Autor des Standardkommentars zum „Bonner Grundgesetz“, noch im hohen Alter Kontakt zu rechtsradikalen Kreisen pflegte. Oder: Was hält Herzog von François Mitterrand, dem er drei, und dem Ehepaar Clinton, dem er eine Seite widmet? Das Interessanteste, was man hier erfährt, ist, dass Herzog mit beiden über ein Thema gesprochen hat, das jeden Politikstudenten bereits im ersten Semester beschäftigt, nämlich den Unterschied und die politischen Folgen von geschlossenen und offenen Exekutiven (S. 172 und 174). Über Helmut Kohl lernt man ebenfalls nichts Neues; ebenso wenig erhellend sind Herzogs Ausführungen zu seiner Wahl 1994. Nach seiner Darstellung erhielt er schon im Mai 1993 erste Anzeichen (S. 152), dass er als Bundespräsident erwogen wurde - ein etwas überraschender Hinweis, denn immerhin war zuerst Steffen Heitmann von den Unionsparteien vorgeschlagen worden (ebenda), was der Vermutung Vorschub leistet, Heitmann sei bloß Spielball politischer Interessen gewesen.

Die letzten Abschnitte des Buches (S. 213 ff.) geben einen Einblick in Herzogs Weltsicht und seine Aktivitäten nach Ende seiner Amtszeit (etwa im europäischen Grundrechtskonvent, S. 295 ff.). Für die Kenner der Materien mag hier noch die eine oder andere Detailinformation schlummern. Ansonsten bietet Herzog recht allgemeine Gedanken zu Themen wie interkulturelle Politik (S. 228 ff.), Globalisierung (S. 213 ff.) oder technischer Fortschritt (S. 264 ff.), wobei er häufig auf gehaltene - mitunter auch nicht gehaltene - Reden zurückgreift. Herzog bleibt auch in diesem Teil seinen Vorgaben treu. Allein bei den am Schluss jedes Kapitels angefügten „Apropos“, in denen er Anekdoten oder „komische Erinnerungen“ (S. 9) präsentiert, blitzt die Ironie auf, für die er bekannt ist.

Die Bücher erfüllen die in sie gesetzten Erwartungen also nicht. Zusammen genommen hinterlassen sie einen irritierenden Eindruck, denn beide - Köhler mehr noch als Herzog haben sich die Erneuerung des Landes auf die Fahnen ihrer Präsidentschaft geschrieben. Herzogs „Ruckrede“ und die öffentlichen Anmerkungen Köhlers zum politischen Tagesgeschäft belegen dies eindrücklich. Daher stießen beide auch schnell an die Grenzen des Amtes, was sie bisweilen zu einer grundsätzlichen Kritik an der Parteiendemokratie provozierte und mit dem Plebiszitären kokettieren ließ. Besonders deutlich wird dies, wenn Herzog am Schluss seiner „Erinnerungen“ eher unmotiviert darüber spekuliert, was er getan hätte, hätten die Parteien sich 1998 - bei einem anderen als dem tatsächlichen Wahlausgang - einer Koalition verweigert. Dann, so Herzog, hätte er eine Große Koalition „erzwungen“: „Zusammen mit einem Staatsvolk, das auf mich hörte, hätte ich das mit ziemlicher Sicherheit bewirken können." (S. 403) Bekanntlich ist uns das - gottlob - erspart geblieben. Ein Volk, das auf einen Präsidenten „hört“, der eine Koalition „erzwingt“, ist keine sonderlich demokratische Vorstellung. 